\title{
Brain-spinal cord ratios in porpoises: Possible correlations with intelligence and ecology'
}

SAM H. RIDGWAY, MARINE BIOSCIENCE FACILITY, POINT MUGU, CALIFORNIA

N. J. FLANIGAN, BIOLOGY DEPARTMENT, ST. NORBERT COLLEGE JAMES G. MCCORMICK, DEPARTMENT OF PSYCHOLOGY, PRINCETON UNIVERSITY

As a rough measure of intelligence, brain weight: cord weight ratios in small delphinids compared favorably with, but were slightly less than, this ratio in man. Not all delphinids studied were found to achieve the minimum $1000 \mathrm{gm}$ brain weight correlate of language development in the human child. The average adult brain size in some small pelagic cetaceans was found to be about $800 \mathrm{gm}$, while the average for Tursiops truncatus, an estuarine species, was found to be about $1450 \mathrm{gm}$.

The Atlantic bottlenose porpoise (or dolphin) Tursiops truncatus has impressed both laymen and scientific investigators as being highly intelligent. McBride \& Hebb (1948) considered the problems of assessing intelligence with special reference to $T$. truncatus. They were only able to conclude that with respect to its emotional and motivational characteristics, the bottlenose porpoise lies somewhere between dog and chimpanzee. Kellogg (1961) classified this porpoise's intelligence between dog and man. Recently Morgane (1965) has found that the cytoarchitectural and laminar differentiation patterns in $T$. truncatus brain compare favorably with higher primates, including man. From behavioral, brain weight, and linguistic studies, Lilly (1961) postulates near-human intelligence for this porpoise.

Through comparisons of brain weight with body weight, body length, and body surface in vertebrates generally and for Cetacea in particular, Dubois concluded that man occupies the highest level (7th) of nervous cephalization, anthropoid apes and odontocetes a 5th group and mysticetes the 4th (van der Klaau, 1948). More recently, Wirz (1950) has regrouped these forms based upon measurements confined to the brain. When the brain is divided into olfactory, neopallial, basal gangliar and cerebellar portions and when these weights are then compared with the "remainder" of the brain (roughly equivalent to the lower brain stem), her system places the odontocetes on a par with man, the mysticetes on a par with other primates.

In addition to his speculation concerning intelligence, Lilly (1964) has made the generalization that no "deepsea adult cetaceans" exist with a brain smaller than 900 to $1000 \mathrm{gm}$, which is a critical minimal correlate of language development in the maturing human child (Lilly, 1961). He goes on to suggest that to live in the sea breathing air with a mammalian physiology and a mammalian skin, requires a large brain for a successful adaptation over the millenia.
Since very little brain weight data exists for the small odontocetes, we decided to test Lilly's minimum brain weight hypothesis and to expand the work of Dubois and Wirz with an interspecies study of brain weight, body weight, and body length in $T$. truncatus, Lagenorhynchus obliquidens, Phocoenoides dalli, and Delphinus delphis bairdi. Also, because Warden (1951) has noted that a rough measure of intelligence among vertebrates is the ratio of the weight of the brain to that of the spinal cord (in fishes the brain weighs less than the cord; in the horse the ratio is about 2.5:1; in the cat 4 or $5: 1$; in apes about $8: 1$; and in man $50: 1$ ), we compared our brain weight data to the cord weights. Subjects and Procedure

The classification, age, and sex of the porpoises used in this study are given in Table 1. Five animals were used (included in Fig. 1) for whom cord data was not

Table 1. Comparisons of body length, body weight, brain and cord weights in some cetaceans.

\begin{tabular}{|c|c|c|c|c|c|c|c|c|}
\hline Sex & Age & $\begin{array}{c}\text { Body } \\
\text { wt, } \\
\mathrm{Kg}\end{array}$ & $\begin{array}{l}\text { Body } \\
\text { Length } \\
\mathrm{cm}\end{array}$ & $\begin{array}{c}\text { Brain } \\
w \dagger, \\
g\end{array}$ & $\begin{array}{c}\text { Cord } \\
\text { wt, } \\
\mathbf{g}\end{array}$ & $\begin{array}{l}\text { Body } \\
\text { Weight } \\
\text { :brain } \\
\text { ratio }\end{array}$ & $\begin{array}{c}\text { Body } \\
\text { Length } \\
\text { :brain } \\
\text { ratio }\end{array}$ & $\begin{array}{l}\text { Brain } \\
\text { :cord } \\
\text { ratio }\end{array}$ \\
\hline
\end{tabular}

\begin{tabular}{|c|c|c|c|c|c|c|c|c|}
\hline \multicolumn{9}{|c|}{ A) Tursiops truncatus } \\
\hline$F$ & adult & 60 & 182 & 1353 & 35 & 44: 1 & 135: 1 & $39: 1$ \\
\hline $\mathrm{F}$ & adult & 102 & 198 & 1588 & 35 & 64: I & 125: 1 & $45: 1$ \\
\hline $\mathrm{F}$ & young & 80 & 158 & 1300 & 32 & $62: 1$ & 122: 1 & $39: 1$ \\
\hline$F$ & adult & 120 & $\underline{235}$ & 1296 & $\underline{36}$ & 93:1 & 181:1 & $36: 1$ \\
\hline$F$ & Average & 91 & 193 & 1384 & 35 & $66: 1$ & 139: 1 & $39: 1$ \\
\hline$M$ & adult & 95 & 182 & 1389 & 31 & $68: 1$ & 131: 1 & $45: 1$ \\
\hline$M$ & adult & 100 & 212 & 1555 & 40 & $64: 1$ & $136: 1$ & $39: 1$ \\
\hline$M$ & adult & 63 & & 1540 & 34 & $41: 1$ & & 45: 1 \\
\hline M & $4 \operatorname{mos}$ & 40 & 133 & $\underline{1268}$ & 35 & 32: 1 & 105: 1 & $36: 1$ \\
\hline$M$ & Average & 75 & 176 & 1438 & $\underline{35}$ & 51:1 & 122:1 & 41:1 \\
\hline \multicolumn{2}{|c|}{ Averoge } & 83 & 185 & 1411 & 35 & $59: 1$ & 131: 1 & $40: 1$ \\
\hline \multicolumn{9}{|c|}{ B) Lagenorhynchus obliquidens } \\
\hline 1 & odult & 79 & 172 & 1079 & 31 & 73:1 & $159: 1$ & $34.8: 1$ \\
\hline$M$ & adult & 110 & 188 & 1285 & 37 & $86: 1$ & 146: 1 & $34.7: 1$ \\
\hline$M$ & adult & 70 & 172 & 1046 & 30 & $67: 1$ & $164: 1$ & $34.8: 1$ \\
\hline M & adult & 100 & 198 & 1136 & 33 & 38: 1 & 174: 1 & $34.4: 1$ \\
\hline \multicolumn{2}{|c|}{ Average } & 90 & 183 & 1137 & 33 & $79: 1$ & $16 \mathrm{I}: 1$ & $34.5: 1$ \\
\hline \multicolumn{9}{|c|}{ C) Phocoenoides dalli } \\
\hline$r$ & adult & 70 & 180 & 760 & 29 & 105: 1 & 236: 1 & $26: 1$ \\
\hline$F$ & adult & 115 & 191 & $948 *$ & $35^{*}$ & 121:1 & 202:1 & $27: 1$ \\
\hline $\mathbf{F}$ & adult & 110 & 185 & 793 & 30 & $139: 1$ & 222:1 & 26: 1 \\
\hline \multicolumn{2}{|c|}{ Average } & 98 & 185 & 834 & 31 & 122: 1 & 222: 1 & $26: 1$ \\
\hline
\end{tabular}

* After one week in formalin 


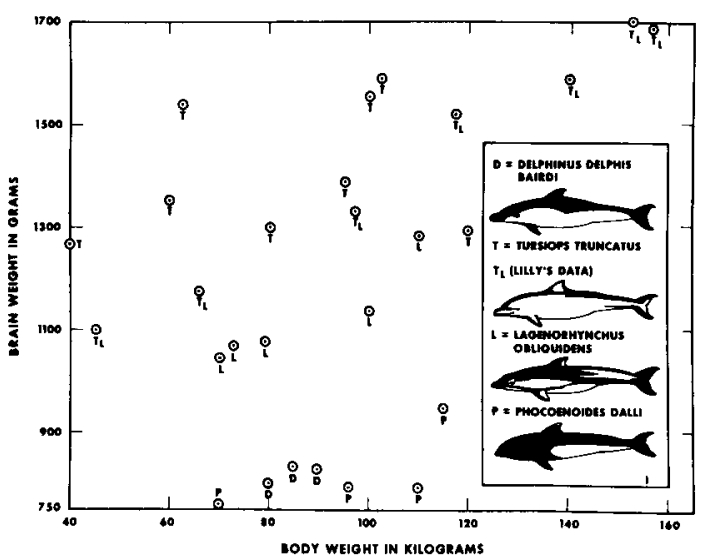

Fig. 1. Comparison of brain weight to body weight data for small delphinids, contrasted with data of Lilly (1964).

taken: One adult male $P$. dalli, one adult female $L$. obliquidens, and three adult male D. bairdi.

When the animal had stranded on a beach or had died in captivity and the necropsy could be performed a shore, actual measurements were made of brain weight, cord weight, body weight and body length. We determined that experienced collectors could estimate the body weight of an adult specimen within 5 percent. When the necropsy was performed at sea, usually for the purpose of quick fixation of the central nervous system, weighing of the whole body was impractical and estimates were used. Ages of these animals were determined on the basis of body size, condition of teeth, and appearance of bone.

The specimens were decapitated so that all transections were made uniformly at the level of the occipital condyles. The brains were removed after dorsal craniotomy. The cords were taken after removing the dorsal spines of the cervical and thoracic vertebra, exposing the spinal canal. With the exception of one brain and cord (see Table 1) all material was weighed in fresh condition.

\section{Results and Discussion}

Although our brain weight data for T. truncatus compares favorably with figures reported by Lilly (1964), we found his minimum brain weight hypothesis to be oversimplified. All specimens of T. truncatus and L. obliquidens did have brain weights over $1000 \mathrm{gm}$; however, none of the P. dalli orD. bairdi had a $1000 \mathrm{gm}$ brain. The D. bairdi and all but one P. dalli brains were below the minimum 900 gm weight which Lilly proposed as a criterion for the adaptation of cetaceans to a marine environment (the one brain over this weight was weighed after one week in formalin). One adult P. dalli had a brain weight of $760 \mathrm{gm}$ (ecological and physiological differences of T.truncatus, L.obliquidens and P. dalli have been defined by Ridgway (1966)).

As seen in Table 1, T. truncatus has the highest ratio of brain weight to spinal cord weight. All $T$. truncatus had higher brain to cord ratios (average 40:1) than all L. obliquidens (average 34.5:1) measured, and, in turn, all L. obliquidens had higher ratios than all P. dalli (average 26:1). These ratios approach the 50:1 ratio given for man (Warden, 1951) and are much higher than those given for subhuman primates (8:1). Therefore, according to Warden's "approximate measure of intelligence," the small delphinids would rank between man and lower primates.

The brain weight and cord weight data presented here represents significant interspecies variation. If the comparative brain structure work of Wirz and Morgane could be repeated on an interspecies basis along with interspecies studies of delphinid behavior, similar to the T. truncatus studies of Kellogg, McBride and Hebb, and Lilly, one should gain a more comprehensive understanding of relative intelligence in the delphinids, and such correlation as may exist between brain, cord ratios and intelligence.

\section{References}

Kellogg, W. N. Porpoises and sonar. New York: University of Chicago, 1961.

Lilly, J. C. Man and dolphin. New York: Doubleday, 1961.

Lilly, J. C. Animals in aquatic environments: adaptation of mammals to the ocean. Handbook of Physiology-environment, 1964. McBride, A. F., \& Hebb, J. Behavior of the captive Bottlenose dolphin, Tursiops truncatus. J. comp. physiol. Psychol., 1948, 41, 111-123.

Morgane, P. J. Lamination characteristics and areal differentiation in the cerebral cortex of the Bottlenose dolphin (Tursiops truncatus). Anat. Rec., 1965, 151 (3), 390-391.

Ridgway, S. H., \& Johnson, D. G. Blood oxygen and ecology of porpoises of three genera. Science, 1966, 151, 456-458.

van der Klaau, C. J. Archives Neerland, de Zoologie, 1948, 1952, $9,1$.

Warden, C. J. Animal Intelligence. Scient. American, 1951, 185, 64. Wirz, K. Acta Anat., 1950, 9, 134.

Note

1. This research was supported in part by a U. S. Public Health Service grant to N. J. Flanigan. We thank F. G. Wood for advice concerning this manuscript. 